This item was submitted to Loughborough's Research Repository by the author.

Items in Figshare are protected by copyright, with all rights reserved, unless otherwise indicated.

\title{
A method for synchronising digitised video data
}

PLEASE CITE THE PUBLISHED VERSION

PUBLISHER

(C) Elsevier

VERSION

AM (Accepted Manuscript)

LICENCE

CC BY-NC-ND 4.0

REPOSITORY RECORD

Yeadon, Maurice R., and Mark A. King. 2019. "A Method for Synchronising Digitised Video Data”. figshare. https://hdl.handle.net/2134/6236. 
This item was submitted to Loughborough's Institutional Repository (https://dspace.lboro.ac.uk/) by the author and is made available under the following Creative Commons Licence conditions.

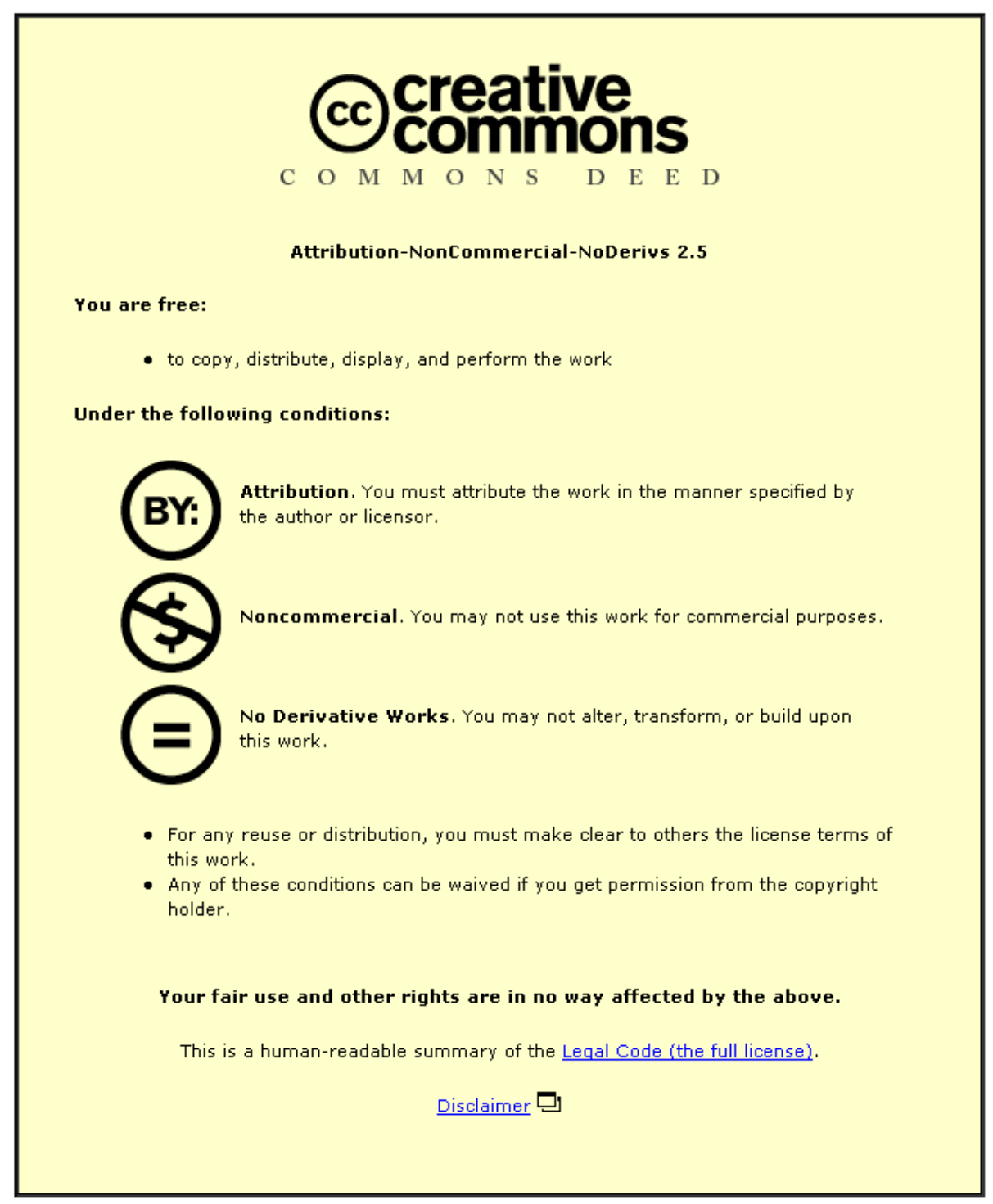

For the full text of this licence, please go to: http://creativecommons.org/licenses/by-nc-nd/2.5/ 


\title{
A method for synchronising digitised video data
}

\author{
M.R. Yeadon and M.A. King \\ Department of Sports Science, Loughborough University, Loughborough, LE11 3TU, UK
}

\begin{abstract}
This paper presents a general method for synchronising digitised video data using a mathematical approach based upon the DLT reconstruction technique. The method was tested using digitised data from genlocked video recordings of gymnastic vaulting, tumbling, high bar and rings. The mean synchronisation error was less than $0.002 \mathrm{~s}$ for vaulting and less than $0.001 \mathrm{~s}$ for the other activities.
\end{abstract}

Keywords: Sports biomechanics, video analysis, synchronisation, DLT

\section{Introduction}

The Direct Linear Transformation (DLT) has been used by many researchers to reconstruct the three-dimensional locations of body landmarks from the digitised coordinates of film or video images. The DLT method requires synchronised digitised data from two or more cameras. Genlocked video cameras or phase-locked cine cameras will produce synchronous data sets but at sports events the required cabling between cameras is not always possible.

Synchronised data may be derived from non-synchronised data sets using interpolation provided that the time corresponding to each video field is known. Blievernicht (1967) placed a rotating cone timer in the field of view to give time values to within $0.005 \mathrm{~s}$ and Walton (1970) used an LED clock to give times to within $0.001 \mathrm{~s}$. However in the sporting arena it is not always possible to place timing devices in the field of view of each camera.

Synchronisation of data sets may be effected to within 0.020 s by identifying fields from each view which correspond to an event such as foot contact with the ground. This can be improved upon by using several such events and fitting a regression line to the corresponding field numbers (Dapena and Chung, 1988). Yeadon (1989) synchronised film of ski jumping to within $0.005 \mathrm{~s}$ using the digitised data at takeoff and landing. This method required that the velocity vector lay in a known plane at takeoff and made a substantial angle with the plane parallel to the camera axes at landing. Pourcelot et al. (1997) synchronised data obtained from 8mm video cameras by minimising the average DLT reconstruction error estimate of a single marker on a rotating wheel. This paper presents a more general method of synchronisation using DLT reconstruction that makes use of the digitised data of all body landmarks and can be used to synchronise digitised data sets of any sports movement.

\section{Method}

\subsection{Data collection}

Gymnastic vaulting, tumbling, high bar and rings were recorded using two genlocked Sony video cameras with a recording frequency of $50 \mathrm{~Hz}$ in order to evaluate a method for synchronising digitised data from different camera views.

\subsection{Data processing}

15 body landmarks (left and right wrists, elbows, shoulders, hips, knees, ankles, toes and centre of head) were digitised in each field. Quintic splines were fitted to the 
digitised coordinate data from the two camera views in order to obtain interpolated values for different time offsets (Wood and Jennings, 1979). The DLT reconstruction method of Karara (1980) was used to obtain the 3D locations of the digitised points:

$$
\mathrm{u}=\frac{\mathrm{L}_{1} \mathrm{X}+\mathrm{L}_{2} \mathrm{y}+\mathrm{L}_{3} \mathrm{z}+\mathrm{L}_{4}}{\mathrm{~L}_{9} \mathrm{X}+\mathrm{L}_{10} \mathrm{y}+\mathrm{L}_{11} \mathrm{z}+1} \quad \mathrm{v}=\frac{\mathrm{L}_{5} \mathrm{X}+\mathrm{L}_{6} \mathrm{y}+\mathrm{L}_{7} \mathrm{z}+\mathrm{L}_{8}}{\mathrm{~L}_{9} \mathrm{X}+\mathrm{L}_{10} \mathrm{y}+\mathrm{L}_{11} \mathrm{z}+1}
$$

where $(\mathrm{u}, \mathrm{v})$ are the digitised coordinates

$(\mathrm{x}, \mathrm{y}, \mathrm{z})$ are the 3D locations of the digitised points

$\mathrm{L}_{1}-\mathrm{L}_{11}$ are the DLT parameters

The 11 DLT parameters for each camera were calculated using two equations (1) for each of a number of digitised calibration points of known location and solving the resulting system of equations using a least squares technique (Stewart, 1973). The number of calibration points varied for the different movements analysed (Table 1).

To reconstruct the 3D location of each digitised body point the DLT equations (1) were rearranged to give two equations for each camera view relating the 3D location of each digitised point to the digitised coordinates.

$$
\left[\begin{array}{ccc}
\mathrm{L}_{1}-\mathrm{L}_{9} \mathrm{u} & \mathrm{L}_{2}-\mathrm{L}_{10} \mathrm{u} & \mathrm{L}_{3}-\mathrm{L}_{11} \mathrm{u} \\
\mathrm{L}_{5}-\mathrm{L}_{9} \mathrm{v} & \mathrm{L}_{6}-\mathrm{L}_{10} \mathrm{v} & \mathrm{L}_{7}-\mathrm{L}_{11} \mathrm{v} \\
\mathrm{L}_{1}^{\prime}-\mathrm{L}_{9}^{\prime} \mathrm{u}^{\prime} & \mathrm{L}_{2}^{\prime}-\mathrm{L}_{10}^{\prime} \mathrm{u}^{\prime} & \mathrm{L}_{3}^{\prime}-\mathrm{L}_{11}^{\prime} \mathrm{u}^{\prime} \\
\mathrm{L}_{5}^{\prime}-\mathrm{L}_{9}^{\prime} \mathrm{v}^{\prime} & \mathrm{L}_{6}^{\prime}-\mathrm{L}_{10}^{\prime} \mathrm{v}^{\prime} & \mathrm{L}_{7}^{\prime}-\mathrm{L}_{11}^{\prime} \mathrm{v}^{\prime}
\end{array}\right]\left[\begin{array}{c}
\mathrm{x} \\
\mathrm{y} \\
\mathrm{z}
\end{array}\right]=\left[\begin{array}{c}
\mathrm{u}-\mathrm{L}_{4} \\
\mathrm{v}-\mathrm{L}_{8} \\
\mathrm{u}^{\prime}-\mathrm{L}_{4}^{\prime} \\
\mathrm{v}^{\prime}-\mathrm{L}_{8}^{\prime}
\end{array}\right]
$$

where $\mathrm{u}^{\prime}, \mathrm{v}^{\prime}, \mathrm{L}_{\mathrm{i}}^{\prime}$ are associated with the second camera.

Equation (2) represents the equations of four planes $P_{i}$ each of the form $\mathrm{a}_{\mathrm{i}} \mathrm{x}+\mathrm{b}_{\mathrm{i}} \mathrm{y}+\mathrm{c}_{\mathrm{i}} \mathrm{z}=\mathrm{d}_{\mathrm{i}}(\mathrm{i}=1,2,3,4)$. Each equation was normalised by dividing through by $\sqrt{a_{i}^{2}+b_{i}^{2}+c_{i}^{2}}$ and a least squares solution $\left(x_{0}, y_{0}, z_{0}\right)$ to the system of four equations was obtained using the method of Stewart (1973) for each digitised body landmark. The residuals $r_{i}$ of the least squares solution were of the form:

$$
\left|r_{i}\right|=\frac{\left|a_{i} x_{o}+b_{i} y_{o}+c_{i} z_{o}-d_{i}\right|}{\sqrt{a_{i}^{2}+b_{i}^{2}+c_{i}^{2}}} \quad(i=1,2,3,4)
$$

which is the distance of $\left(\mathrm{x}_{0}, \mathrm{y}_{0}, \mathrm{z}_{0}\right)$ from the plane $\mathrm{P}_{\mathrm{i}}$ (Fuller and Tarwater, 1986).

The RMS distance $r$ of each 3D location from the four planes was calculated using:

$$
r=\sqrt{\frac{r_{1}^{2}+r_{2}^{2}+r_{3}^{2}+r_{4}^{2}}{4}}
$$

The RMS distance was calculated for each point digitised in each field throughout the whole movement. To obtain an overall RMS error estimate for each trial over all the points and fields the global RMS distance R was calculated using equation (5). 


$$
R=\sqrt{\frac{\sum_{j=1 i=1}^{n} \sum_{i j}^{15} r_{i j}^{2}}{15 n}}
$$

where

$$
\begin{array}{ll}
\mathrm{r}_{\mathrm{ij}} & =\text { RMS distance } \mathrm{r} \text { for body landmark } \mathrm{i} \text { in field } \mathrm{j} \\
\mathrm{n} & =\text { number of fields } \\
15 & =\text { number of points digitised on the body in each field. }
\end{array}
$$

The global RMS distance represents an overall error estimate of the reconstruction accuracy of the digitised body landmarks and will be affected by a number of factors including digitisation errors, lens distortion and synchronising errors. The global RMS distance will tend to be smallest when the digitised data sets are correctly synchronised since all other errors will be the same or similar for different time offsets. The two digitised data sets were therefore synchronised by varying the time offset between them until the global RMS distance was minimised.

To evaluate the new technique for calculating the time offset between the digitised data from two camera views, the actual time offset was required. Since the video recordings were genlocked the actual time offset could be determined using common events from each camera view. The difference between the actual and predicted offset was then determined to evaluate the accuracy of the method for synchronising digitised data from different camera views.

For genlocked cameras it is to be expected that the splines will be evaluated close to the field times and so give coordinate values close to the original digitised data. In the case of data sets that are not synchronised the splines will be evaluated away from the field times. To see what effect, if any, this has on the synchronisation accuracy a pseudo data set was generated at mid-field times for one camera for every data set by averaging coordinate values for adjacent fields.

\section{Results}

Table 1 shows a summary of the camera / calibration set-ups used for each activity analysed. The accuracy of the DLT reconstruction was obtained by comparing the known locations of the calibration points with their reconstructed locations. Average unbiased root mean square estimates of the coordinate errors in the calibration points varied from $0.010 \mathrm{~m}$ to $0.011 \mathrm{~m}$ over the range of camera / calibration set-ups used for the different movements (Table 1).

The variation of the global RMS reconstruction distance $\mathrm{R}$ with synchronisation offset time $t$ is shown for one circling movement on the high bar (Figure 1). The relationship between $\mathrm{R}$ and $\mathrm{t}$ is given by the hyperbola $\mathrm{R}^{2}=\sigma^{2}+\mathrm{k}^{2} \mathrm{t}^{2}$ where $\sigma$ is the (minimum) RMS distance corresponding to a synchronisation offset of zero.

The accuracy of the synchronisation method was obtained by comparing the known offset with the calculated offset. The mean (absolute) synchronisation error over all the sports analysed was $0.0005 \mathrm{~s}$ (Table 2).

By averaging data from adjacent fields for one camera view it was possible to evaluate the method for offsets of $0.010 \mathrm{~s}$. The magnitudes of the synchronisation errors for offsets of $0.010 \mathrm{~s}$ were very similar to those for the time offsets of zero and had the same mean synchronisation error of 0.0005 s (Table 3). 


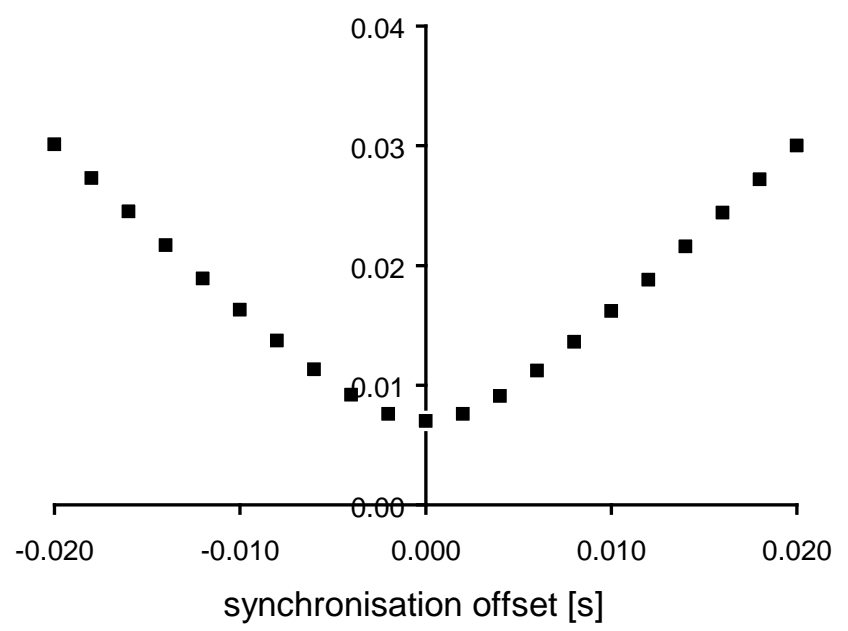

Figure 1. RMS distance errors for different synchronisation offsets for one high bar trial.

Table 1. Summary of camera / calibration set ups used for each sport

\begin{tabular}{|l|c|c|c|c|}
\hline & vaulting & tumbling & high bar & rings \\
\hline recording format & Hi8 & Hi8 & Hi8 / Digital & Hi8 \\
\hline calibration points & 19 & 19 & 28 & 16 \\
\hline field of view [m] & 6 & 6 & 7 & 9 \\
\hline DLT error [m] & 0.011 & 0.011 & 0.011 & 0.010 \\
\hline
\end{tabular}

Table 2. Summary of digitised data / synchronisation errors

\begin{tabular}{|l|c|c|c|c|}
\hline & vaulting & tumbling & high bar & rings \\
\hline number of trials & 3 & 5 & 6 & 6 \\
\hline average number of fields & 41 & 50 & 111 & 173 \\
\hline average RMS distance [m] & 0.012 & 0.014 & 0.009 & 0.009 \\
\hline mean sync error [s] & 0.00167 & 0.00034 & 0.00022 & 0.00030 \\
\hline max sync error [s] & 0.00362 & 0.00079 & 0.00061 & 0.00038 \\
\hline min sync error [s] & 0.00063 & 0.00004 & 0.00003 & 0.00027 \\
\hline
\end{tabular}


Table 3. Synchronisation errors for 0.010 s offset

\begin{tabular}{|lc|c|c|c|c|}
\hline & & vaulting & tumbling & high bar & rings \\
\hline mean sync error & {$[\mathrm{s}]$} & 0.00160 & 0.00036 & 0.00021 & 0.00032 \\
\hline max sync error & {$[\mathrm{s}]$} & 0.00352 & 0.00070 & 0.00060 & 0.00052 \\
\hline min sync error & {$[\mathrm{s}]$} & 0.00051 & 0.00004 & 0.00000 & 0.00017 \\
\hline
\end{tabular}

\section{Discussion}

This study has examined whether it is possible to synchronise digitised data from different camera views using a mathematical approach based upon the DLT reconstruction technique. Since the method uses the digitised data to determine the synchronisation offset, the accuracy of the method will be dependent on the accuracy and range of the digitised data. Since the relationship between the RMS distance and the synchronisation offset is hyperbolic (Figure 1), the minimum may be located by fitting a hyperbola to a number of points. This procedure has the potential to increase the speed of calculation and to improve the accuracy of the estimated synchronisation offset.

The synchronisation method of Yeadon (1989) for ski jumping landings only performs well when the mass centre velocity makes a large angle with the plane parallel to the two camera axes. For the takeoff in ski jumping this angle is small and knowledge of the vertical plane containing the velocity vector is also required. The method of Pourcelot et al. (1997) using a single marker will perform well if the marker velocity makes a sufficiently large angle with the plane of the camera axes at some time during the movement. The method presented here makes use of all body landmarks but in a more comprehensive way than Yeadon (1989) and also uses information from all video fields of the movement in the same way as Pourcelot et al. (1997). As a consequence the present method will perform well so long as the velocity of some body landmark makes a large angle with the plane of the camera axes at some time during the activity. The synchronisation errors for vaulting were higher than the errors for the other three activities. It is likely that this was due to camera alignment, small changes in velocity and little relative limb movement during the phase of the vault analysed.

This method for synchronising video data has a number of advantages over previous methods. It does not require timing devices to be placed in the field of view and therefore can be used in competitive environments where this may not be possible. It can be used with a wide range of movements since it uses all the digitised data to synchronise the camera views. It is more accurate than previous methods which use the digitised data for synchronisation. In addition the method provides a check that genlocked cameras were in fact genlocked and that corresponding fields have been correctly identified. The method may also be used with a 12 parameter DLT which compensates for radial image distortion. Additionally the method has the potential to synchronise digitised $16 \mathrm{~mm}$ film data although the relative framing rates between the two cameras would also have to be included as an additional parameter to be determined. 


\section{References}

Blievernicht, D., 1967. A multidimensional timing device for Cinematography. Research Quarterly 38, 146-148.

Dapena, J., Chung, C.S., 1988. Vertical and radial motions of the body during the takeoff phase of high jumping. Medicine and Science in Sports and Exercise 20, 290302.

Fuller, G., Tarwater, D., 1986. Analytic Geometry, 6th ed., p. 310. Reading, MA: Addison-Wesley.

Karara, H.M., 1980. Non-metric cameras. In: Atkinson, K.B. (Ed.), Developments in close range photogrammetry - 1. Applied Science Publishers, London, pp. 63-80.

Pourcelot, P., Audigié, F., Degueurce, C., Denoix, J.M., Geiger, D., 1997. A numerical method to synchronise home video cameras using the D.L.T. method. Medical and Biological Engineering and Computing 35, Supplement Part 2, 715.

Stewart, G.W., 1973. Introduction to matrix computations, pp. 245-249. London: Academic Press.

Walton, J.S., 1970. A high speed timing unit for Cinematography. Research Quarterly 41, 213-216.

Wood, G.A., Jennings, L.S., 1979. On the use of spline functions for data smoothing. Journal of Biomechanics 12, 477-479.

Yeadon, M.R., 1989. A method for obtaining three-dimensional data on ski jumping using pan and tilt cameras. International Journal of Sport Biomechanics 5, 238-247. 